\title{
The functions of self-initiated self-repair in the second language Chinese classroom ${ }^{1}$
}

\begin{abstract}
Self-repair analysis has often been used to gauge a learner's proficiency level, language acquisition or monitoring ability. This study questions these presumed links by examining the self-initiated self-repair practices of second language learners of Mandarin Chinese drawing from both classroom interaction data and stimulated recall interviews. While this link may not be as strong as previously suggested, self-repair behaviour can reveal other information about the learner, including monitoring preferences, learning strategies, areas of difficulty, and perceptions about both their proficiency level and the target language. As such, self-repair still appears to play an important role in the language learning process, albeit not the straightforward role that has often been assumed to date.
\end{abstract}

Keywords: Self-repair, Mandarin Chinese, classroom, monitoring, proficiency, functions

\section{INTRODUCTION}

Research in second language (L2) acquisition frequently treats self-repair as a process that a learner performs automatically as a result of monitoring and error-detection. As such, it has been linked to a number of aspects of language learning, including proficiency level, progress in language acquisition, and monitoring focus and ability (Fincher 2006; Kormos 1999a; Lennon 1994; O’Connor 1988; Smith 2008; van Hest 1996).

While research has continued to focus on the seemingly automatic processes involved in L2 self-repair, some studies have found that it functions beyond the scope of error correction and resolving misunderstandings. Learners are actually able to control their use of self-repair to promote learning, adhere to social expectations, and improve their own understanding of the target language by 'talking through' their troubles (Buckwalter 2001; Liebscher and Dailey-O’Cain 2003; Rylander 2004). However, these findings appear to diminish the extent to which self-repair can be treated as a straightforward indicator of proficiency and language acquisition.

Research has found that numerous variables both inside and outside the language classroom influence self-repair behaviour, with most attention given to those variables that concern task demands and situational constraints (Kormos 1999a; Smith 2008). Some studies have focused on the effects of individual learner differences, suggesting that learners' preferences, past experience and perceptions of the target language can also shape self-repair behaviour (Fincher 2006; Kormos 1999b; Seliger 1980). In light of the various functions that self-repair appears to perform in language learning, this study sought to examine the nature of self-repair in terms of (1) how learners employ selfinitiated self-repair as a resource for achieving their language learning goals, and (2) how

\footnotetext{
${ }^{1}$ The term Chinese is used as a cover term for all the different Chinese languages and dialects, as well as in some cases to a particular variety, namely, Mandarin Chinese. The term Mandarin is also sometimes used as a short-hand term for the latter. We consistently employ the term "Mandarin Chinese" in this paper to avoid this ambiguity.
} 
these findings impact on our understanding of the import of self-repair practices in second language learning more generally.

In this study, the interactions of four L2 learners in a Mandarin Chinese classroom in Wuhan, China were recorded over a period of two months. Instances in these classroom interactions where these participants were involved in self-initiated self-repair sequences were then transcribed for further analysis. Each of the participants also participated in stimulated-recall interviews in order to gain further insight into the perceived functions of those self-repairs, and, where available, provide additional evidence to support our analysis of their self-repair behaviour in the interactional data.

\section{PREVIOUS STUDIES}

Repair is characterised as "practices for dealing with problems or troubles in speaking, hearing, and understanding the talk in conversation (and in other forms of talk in interaction)" (Schegloff 2000: 207), and thus goes beyond a narrow focus on error correction. It plays a vital role in interaction since it is the only speech act capable of displacing further utterances until the trouble source is either resolved or abandoned. Repair is generally classified into four categories based on who has initiated the repair and who has taken steps to resolve it: self-initiated self-repair (SISR), other-initiated selfrepair (OISR), self-initiated other-repair (SIOR) and other-initiated other-repair (OIOR) (Schegloff 1997, 2000). The terms 'self' and 'other' in self-repair and other-repair refer to the originator of the trouble source and the recipient respectively. Repair was initially studied in the context of L1 speaker interactions, where there is an extensive literature illustrating the use of repairs by native speakers in various languages (cf. Fox and Jasperson 1996; Fox, Hayashi and Jasperson 1996; Hayashi 1994; Schegloff 1979, 1997, 2000; Schegloff, Jefferson and Sacks 1977). Two key findings are that there is a general preference for self-repair over other-repair, and that there is considerable individual variation in the deployment of such practices (Fox and Jasperson 1996; Schegloff, Jefferson and Sacks 1977).

The study of repair has also been extended to the analysis of interactions involving L2 speakers (Rieger 2001, 2003a, 2003b; Rylander 2009; Wong 2000, 2005; see van Hest, Poulisse \& Bongaerts [1997] for a good overview), although in some instances this has been accompanied by a narrowing of focus onto error monitoring and correction, partly due to the tendency for L2 speakers themselves to attend more to errors than L1 speakers (Temple 1992). Errors involve troubles with linguistic forms. Lennon (1994: 89), for instance, defines an error as the production of "a linguistic form, combination of forms, or utterance which, in the same context and under similar conditions of production, would, in all likelihood, not be produced by the subjects' native-speaker counterparts." On this view, self-correction refers to instances where "the speaker edits out of production a segment of discourse and replaces it with an alternative version” (Lennon 1994: 87). Errors are generally used to refer to issues with grammatical forms (i.e., syntactic, morphological, lexical errors). While some authors have extended this to so-called "pragmatic errors" or "content errors" and the like, these terms presuppose a prescriptive standard which is much more difficult to define in contrast to grammatical errors. Thus, in this study the term error is reserved for grammatical ones. 
The focus of this paper, however, is more broadly on self-initiated self-repair (SISR), which refers to instances where the learners launch repair sequences arising from troubles they are experiencing in speaking, hearing or understanding Mandarin Chinese in their classroom interactions. Since the L2 learner produces SISR of their own accord, many studies have focused on SISR to examine its possible link to second language (L2) proficiency, self-monitoring ability and language acquisition (cf. Wong 2000, 2005 and Rylander 2009 on other-initiated repair involving L2 speakers). Such an approach treats SISR as if it were an automatic process resulting from error detection. However, this may not always be the case.

A number of studies have claimed that SISR can be used as an indicator of an L2 learner's proficiency level based on the relationship found between monitoring and proficiency (Bardovi-Harlig and Dornyei 1998; Chen 1990; Fincher 2006; van Hest 1996). Within the context of theories of monitoring it is suggested that items within the target language that are less familiar to the learner are more likely to produce errordetection than more familiar ones (Mackay 1987). In other words, those aspects that have become automated or acquired, and therefore familiar to the learner, are less likely to generate the learner's awareness or prompt the learner to monitor for correctness. Camps (2003) also suggests that the L2 learner's ability to monitor and detect errors when speaking is related to their knowledge of the target language, and subsequent errors could be the result of not knowing the correct form. Self-repair arising as a result of other trouble sources, such as pragmatic inconsistency or inappropriate information, is also said to be indicative of a learner's proficiency in that it can show their capability and awareness of aspects of the target language. The problem with this approach, however, is that the learner's monitoring does not always result in self-repair, even when they believe they have made a mistake. SISRs therefore do not reveal a complete representation of the learner's ability to monitor their own speaking.

Other studies have linked enhanced self-repair ability and strategies to high proficiency levels (Chen 1990; Fincher 2006; van Hest 1996). Chen (1990) investigated differences between the types of communicative strategies that high and low proficiency learners use to compensate for linguistic gaps. High proficiency learners were found to produce fewer but more efficient strategies for repairing conversation. Chen concluded from these results that the frequency, type and effectiveness of communicative strategies vary according to a learner's proficiency level, and that the effectiveness, style and frequency of their self-repairs can therefore be regarded as indicative of a learner's level of proficiency.

However, there are still discrepancies concerning the link made between selfrepair and L2 proficiency. Studies have shown varying and inconsistent results regarding the differences between high and low proficiency learners' ability to self-repair and the frequency of self-repairs (Kormos 2000; van Hest 1996), the frequency of each type of self-repair and awareness of error types (Bardovi-Harlig and Dornyei 1998), and use of communicative strategies in self-repair (Chen 1990). Furthermore, since self monitoring can be affected by variables such as the nature of the task and time demands, the outcomes of error detection may not truly reflect the learner's actual monitoring ability or their proficiency level. The extent to which a learner's monitoring ability truly depends on their level of proficiency is therefore debatable. 
As previously noted, some researchers have treated self-repair as an indicator of language acquisition (Fincher 2006; Lyster 1998). When a learner begins to test hypotheses and to notice the gap between what they produce and the language of native speakers, they are able to acquire new language (Schmidt and Frota 1986). The vehicle for this is monitoring, both of one's own and other's speech. By self-repairing, learners are producing modified output, which as Swain (1995: 191) argues, "represents the leading edge of a learner's interlanguage” and is a vital process for language acquisition (Lyster 1998). Researchers have used this observation to suggest that self-repair can then be used to gauge progress in second language acquisition.

Studies that have used analysis of self-repair data to make inferences about progress in language acquisition, however, have tended to focus on the learner-related processes of error-correction. They have therefore overlooked the controlled processes by which students actively decide when, how and what to repair. Several studies have found that learners may use self-repair for purposes beyond error-correction and resolving misunderstandings (Buckwalter 2001; Fincher 2006; Liebscher and Dailey-O’Cain 2003; Rieger 2001; Rylander 2004).

Buckwalter (2001), for instance, examined the nature of self-repair produced during collaborative pair work. It was found that when working in pairs, learners used self-repair as a metacognitive method for self-regulation of their utterances and used metalinguistic terms in their L1 to "talk through" troubles or potential problems with the language. This illustrates an additional function of self-repair, namely, as a resource for language learning. This function was also identified in Fincher's (2006) study, which found that participants used a number of communicative strategies particular to selfrepair. These strategies included asking in the target language, guessing, using rising intonation, repetition or hesitation, and checking by repeating with several variations. Fincher found in interviews with participants that they employed self-repair strategies for various language learning purposes. Evidence from other studies points to still other roles for self repair. Rylander (2004) and Liebscher \& Dailey-O'Cain (2003) found that learners use self-repair to enact roles within a given context, to adhere to expectations, and to learn "how to do conversation", which contributes to their understanding of certain discourse types. That learners can choose to employ self-repair as a resource for goals other than error-correction and resolving misunderstandings suggests that the extent to which self-repair behaviour can be taken to be indicative of language acquisition, proficiency level and monitoring ability is less clear-cut than has been assumed.

The current study thus sought to further investigate these additional functions of self-repair, as well as variables that affect the use of self-repair, with the view to contributing to the ongoing debate about the accuracy of interpretations about proficiency level, monitoring ability and language acquisition that draw from self-repair data. To examine the functions of self-repair practices of Mandarin Chinese L2 learners, we posited the following two research questions:

(1) What SISR practices are used in a second language Mandarin Chinese classroom?

Our aim was to determine how the participants oriented to trouble sources in their own talk and how they structured their subsequent self-repairs. This interaction data also provided grounds for discussion in the stimulated-recall interviews that followed.

(2) What do participants report as the functions of their SISR in the language classroom?

Our aim was to improve understanding of how participants use self-repair as a resource 
for more than just error correction and resolving misunderstandings. The controlled use of self-repair for these other functions indicates the connection between self-repair and proficiency or monitoring ability may be less straightforward than previously thought.

\section{METHODOLOGY}

This study was conducted over a three month period at Wuhan University in China, in the context of a Mandarin Chinese as a second language program. Thus, both the target language and the language of instruction were Mandarin Chinese. The researcher who collected the data is a native speaker of English with advanced proficiency in Mandarin Chinese. Since her age and status were similar to that of the participants, her presence in the class as an observer appeared to have a minimal impact on participant interactions. The class for observation and recording was selected according to: (a) the proficiency level of the students, (b) the frequency of teacher-student interactions, (c) the potential for students to initiate self-repair due to the course subject matter and focus, and (d) the suitability and willingness of students to participate in the project.

\section{Participants:}

Students in the selected class were considered to share a similar proficiency level, as determined by their results in the Hanyu Shuiping Kaoshi (Modern Standard Chinese Language Proficiency Test), and confirmed by an independent native speaker of Mandarin Chinese. The selected class was at lower-intermediate level and contained a mixture of Asian, European and Anglo students. This level was chosen because the students were thought to be proficient enough to attend classes with Mandarin Chinese as the medium of instruction, but their language usage and learning would not be fully automated. The class teacher was a young Chinese female who could speak English after studying it at a university in China. She made it known to the students early in the program that she could speak English quite fluently, but that classes would be conducted in Mandarin Chinese.

The researcher chose four people from the class as participants in, and focus of, this study. Participants 1 and 2 were male, one from the United States and the other from England. Both had learned the majority of their Mandarin Chinese language within China, primarily through informal instruction. Participants 3 and 4 were both young women from Belgium, who had received all of their Mandarin Chinese language training at home universities and had not been to China before. Both had studied English in Belgium, and their proficiency was at an advanced level, enabling them to participate in stimulated-recall interviews for this research. Proficiency in English was an important criterion in selecting participants, as they needed to be able to discuss in English with the researcher their self-reflections on their Mandarin Chinese language use and self-repair practices in the stimulated recall interviews, since their level of Mandarin Chinese would not allow them to do so. The remaining students in the class had no or insufficient proficiency in English to be able to participate in the interviews.

\section{Task:}

A speaking class was chosen due to the content based structure of the lessons, which encouraged students to participate in open discussions on various topics. The speaking 
classes followed a regular format. The first half of the class involved the teacher explaining grammar points and vocabulary from the textbook, while the second half was reserved for student-directed learning activities. For example, in the second half of class, students were given some time to prepare information on a topic beforehand for presentation tasks, but the tasks also involved impromptu speech production during class discussions and question time. Other tasks included debates that gave students little time for preparation and were mostly spontaneous. The researcher chose to record these interactions in the second half of class because the amount of student talk produced in them was greater than in the first half of class where teacher talk was dominant.

\section{Data Collection:}

Audio recordings supplemented with classroom observation were chosen as the primary methods for collecting classroom interaction data. The initial stage of data collection lasted two months. The classes were held three times a week with each class lasting an hour and a half. After all the recordings were made and examined for relevance and sufficient frequency of self-initiated self-repairs, six recordings were chosen for further analysis, making a total of nine hours of audio-recorded data collected from the classroom.

The second stage of data collection involved one 30 minute stimulated recall interview per participant which was conducted within one week of the conclusion of the phase of recording classroom interactions. The researcher played back the recording of classroom discourse involving the participant, and the participants were instructed to stop the recording themselves when they identified a self-repair, and to comment on their motivations for this self-repair. The participants were not provided with definitions, but rather explained their understanding of and motivations for the self-repair in their own terms. Rather than representing an attempt to quantify the reasons and functions for selfrepair, then, the purpose of the interviews was to gain insight into each participant's views on the various functions of the self-repair practices they had used and to learn from the participants how they decided to initiate repair. The interview was semi-structured, and the participants' answers led into a broader discussion of their general focus in monitoring, the factors that influence this, their choice of repair strategies, and why they had chosen these strategies. The researcher favoured stimulated-recall interviews because, by fostering participants' introspection, they provide insight into the participants' self-reported intentions and purposes when initiating self-repair. The format of the interviews enabled participants to discuss their interactions on a personal level, thus adding an extra dimension to the data that cannot be deduced from the recordings themselves.

There are, however, limitations in using stimulated-recall interviews. These relate specifically to the length of time over which participants can effectively recall useful and accurate information about their own actions. To reduce the possibility of participants creating a false reconstruction of past behaviour, the participants were asked to comment only when they could hear themselves making a repair and felt they could discuss it.

\section{Data Analysis:}

Once the classroom data was collected, the sections of recording containing almost exclusively student talk (i.e., from the second half of the speaking class) were transcribed 
using both Chinese characters and pinyin, and then translated into English with an accompanying morphological gloss. Due to the small size of the data set and the similar level of proficiency of the participants, the data was collated to show overall trends in the frequency of self-initiated self-repair practices. To transcribe the data, we employed the help of a native speaker of Mandarin Chinese. This person also reviewed and contributed to the analysis of self-repairs in the data to ensure greater validity of our analysis. Each line in the examples is numbered and speakers are identified as P1-4 (participants) or T (teacher). The transcription conventions are as follows:

\begin{tabular}{ll}
$<\quad>$ & trouble source \\
underlining & $\begin{array}{l}\text { self-initiated self-repair practice } \\
\text { rising intonation }\end{array}$ \\
\hline$?$ & timed pause \\
$(0.5)$ & micropause \\
$()$. & tones of a word, e.g., (2) second tone \\
$(\#)$ & particle \\
P & nominative \\
NOM & counter \\
C & negation \\
$\mathrm{N}$ &
\end{tabular}

\section{TYPES AND FUNCTIONS OF SELF-INITIATED SELF-REPAIRS}

We analysed the transcriptions seeking to identify the four participants' self-inititated self-repair practices. We did not use the existing taxonomies, for example, those developed by Levelt (1983) and expanded upon by Kormos (1998), since these are generally used for classifying types of trouble sources, particularly grammatical errors. This consequently involves analysis from a teacher's perspective, which is not consistent with the focus in this study on elucidating the learner's perspective on self-repair. We then classified the different types of self-repair practices identified in this study into five broad categories drawing from the categorisations produced by the learners themselves: 'replacement', 'addition', 'asking in (Mandarin) Chinese', 'checking', and 'codeswitching'. We did not provide these terms to the learners, but rather used them to encompass the folk categorisations produced by the learners. The terms we use here are thus not always the same as used by the learners, although we were careful to ensure they matched in terms of their overall definition. 'Repetition' was also found to be important in self-repair sequences, though it is not exclusively used as a self-repair practice (cf. Rieger 2003a).

An explanation and analysis of examples of each type of self-initiated self-repair practice is first provided, along with an overview of the attested functions of each practice based on data from the stimulated-recall interviews. A discussion of what information, if any, the nature and function of each participant's self-initiated self-repair practices can provide about the participants' monitoring and repair habits then follows.

\section{Addition:}


This practice involves participants identifying a trouble source in terms of information lacking in their utterance, then interrupting their own speech to insert what they perceive as information necessary to complete their utterance. ${ }^{1}$

1 P1：个人自述 (0.5) 你写你想博士(.)你想学什公(.)

Ge ren zishu (0.5) ni xie ni xiang boshi ni xiang xue shenme personal statement you write you want $\mathrm{PhD}$ you want study something

2 你想知道 $(0.5)$ 这个东西是更重要(.)

ni xiang zhidao (0.5) zhe ge dongxi shi geng zhongyao

you want know this $\mathrm{C}$ thing is more important

3

更重要<比考试>重要

$<$ geng zhong yao > bi kaoshi zhongyao

$<$ more important $>$ than test important

'A personal statement you write that you want a $\mathrm{PhD}$, you want to study something, you want to know this thing is more important, $<$ more important $>$, it's more important than the test'

In line 3 in example (1) above, the learner repeats 'more important' before initiating selfrepair by adding bi kaoshi ('than the test') in order to clarify that the personal statement is more important than the test.

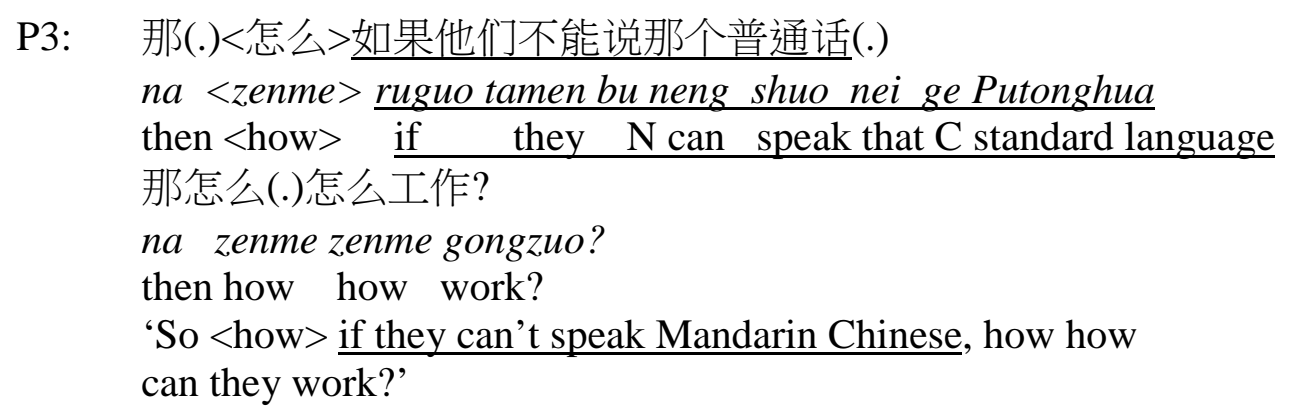

In example (2), the learner interrupts her utterance zenme gongu ('how can they work') (across lines 1-2) and inserts ruguo tamen bu neng shuo nei ge Putonghua ('if they can't speak Mandarin Chinese') (in line 1) as a form of self-initiated self-repair. The self-repair practice of addition functions to ensure comprehension. In other words, in this kind of self-repair practice, learners insert an additional qualification or clarification in their utterances in an attempt to ensure that others participating in the conversation have understood the intent of their question. Learners frequently produced additions depending on how correct they perceived their speech to be or whether they felt listeners had understood them.

\section{Replacement:}

This self-initiated self-repair practice occurs when participants identify a trouble source in their own speech and replace it with something they perceive to be more correct or appropriate within their own turn. 
(3)

1 P4: 因为那个<法国>法语说的人他们不喜欢

yinwei nei ge <faguo $>$ fayu shuo de ren tamen buxihuan because that $\mathrm{C}<$ French $>$ French speak NOM person they $\mathrm{N}$ like 学荷兰语(0.5)因为他们觉得<跟荷兰语没有 $>$ xue helanyu (0.5) yinwei tamen juede < gen helanyu mei you> study Dutch because they think < with Dutch N have> 学荷兰语没有真的没有用所以他们从来没有学过荷兰语

xue helanyu mei you zhende mei you yong study Dutch $\mathrm{N}$ have really $\mathrm{N}$ have use 'Because $<$ French $>$ French speaking people, don't study Dutch because they think there's no use < with Dutch $>$ studying Dutch is not, is really not useful'

Here the learner identifies in line 1 the trouble source as the word faguo ('France') preceding ren ('person'), and replaces it with fayu shuo de ('French speaking') in order to indicate that the people are not French (i.e., from France), but rather French speaking Belgians. In line 2, this learner also identifies gen ('with') as a trouble source and replaces it with xue ('studying'). She used the self-repair practice of replacement to express her intended meaning more effectively.

The use of such practices to convey intended meaning was confirmed in the stimulated-recall interviews. For instance, participant 2 claimed:

(4) I alter my speech when I realise that I can't make the desired point using the construction I am using. (P2, emphasis added)

This differs from ensuring comprehension in that learners strive to express themselves in exactly the way they want, rather than compromising for the sake of ensuring understanding by others.

\section{Asking in Mandarin Chinese:}

In this self-repair practice, participants interrupt their own speech to ask for a word, using Mandarin Chinese to phrase the question and English for the target word. The speaker does so after noticeable disfluencies in his or her prior speech.

$1 \mathrm{~T}$ : 所以如果中国要高考(.)就是同样的考试(.) suoyi ruguo zhongguo yao gaokao (.) jiushi tongyang de kaoshi (.)

2 谁告诉你们? so if China need exam then same NOM exam

shei gaosu nimen?

who tell you(plural)

'So if Chinese need an entrance examination to get into the civil service, it's the same exam. Who told you that?'

3 P1: 中国的朋友 $(0.5)$ 就是(.) 就是 $<$ 你不 $>$ 你没没 $<$ pass $>$ 怎么说? 


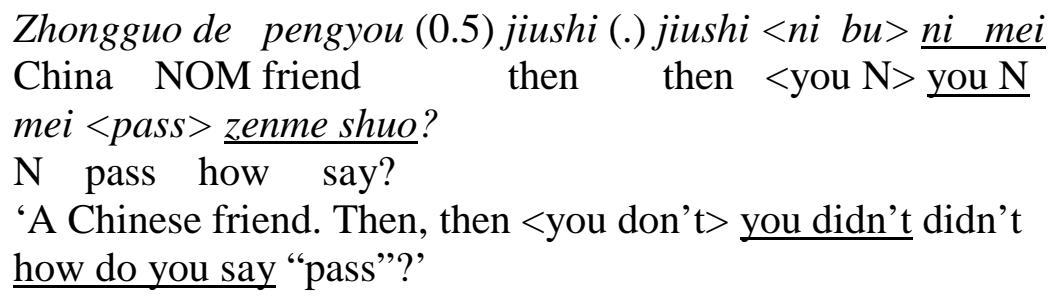

In line 3 in this example, the learner interrupted his intended utterance ni meiyou tongguo kaoshi ('if you didn't pass the test') with a self-repair sequence, explicitly asking how to say 'pass' (in Mandarin Chinese) in response to the teacher's question (lines 1-2). This self-repair was preceded by disfluencies in the form of repetition.

Participants confirmed that they were most likely to use this self-initiated selfrepair practice when they realised they did not know a word or when they were uncertain about an expression. For instance, participant 2 said in the interview that:

(6) I didn’t know how to say 'Central Asia’ so I just asked for it in English. (P2)

Participants confirmed that the main function of asking for a word in Mandarin Chinese was for language learning purposes. They initiated self-repair of their speech by asking for words in Mandarin Chinese to enhance their knowledge of the target language, particularly their knowledge of vocabulary.

\section{Code-switching:}

Code-switching is very similar to "asking in Mandarin Chinese” except here the speaker does not raise their intonation and does not phrase the code-switch into English as a question or an indication of their need for feedback. The main sequence that these selfrepairs exhibited was a code-switch into English after either some attempts to express the meaning in Mandarin Chinese, or a noticeable disruption in otherwise fairly fluent speech.

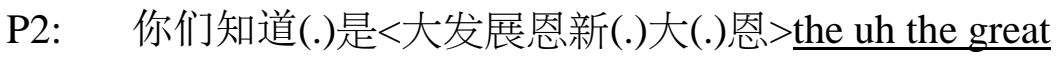
nimen zhidao (.) shi <da fazhan en xin da en> the uh the great you[plural] know is big development $\mathrm{P}$ new big $\mathrm{P}$ the uh the great western development western development 'You know <it's the great development uh new big uh> the uh the great western development'

In Example (7), the learner was evidently trying to say da xifang fazhan ('great western development') in various ways and exhibited several disfluencies before initiating selfrepair by code-switching to English. Here the learner noted in the later interview :

(8) I want [to] tell them about the 'Great Western Development', a Chinese government policy. I begin to say it in [Mandarin] Chinese but realise I don't know how to say policy and that maybe it's different in [Mandarin] Chinese so I switch to English. (P2) 
Although this self-repair practice is similar to asking in Mandarin Chinese, learners used it primarily to cover for language deficiencies, rather than for language learning per se. In particular, they sought to express their intended meaning, but rather than abandon the attempt upon realising they lacked appropriate vocabulary to express this, they codeswitched into English.

\section{Checking:}

In this self-initiated self-repair practice, the participants interrupt their utterances by repeating the perceived trouble source in various ways, often using rising intonation to signal their need for feedback. The difference between the repetitions used in checking and those resulting from disfluencies is that they either tended to vary slightly in terms of tonal pronunciation or word order, or were marked with rising intonation generally without the use of fillers such as 'uhm' and 'ah'. The participants may have also used the English word proceeding or following the "checking” self-repair.

P1: 还有(.)就是你是一个<学者>?(.)学者?

Hai you jiushi ni shi yi ge <xue(2)zhi(2)>?(.)xue(2)zhi(3)?

still have then you is one $\mathrm{C}<$ scholar $>\quad$ scholar

2

你要跟(.)跟別的学校跟別的学者联系

ni yao gen gen bie de xuexiao gen bie de xue(2)zhi(3) lianxi

you need with with other NOM school with other NOM scholar connect

'Also, if you're a <scholar> scholar you have to connect with other schools, with other scholars'

3 T: 学者

хие(2)zhe(3)

scholar

'scholar'

4

P1: 哦学者(.)别的地方联系

$o$, xuezhe (.) bie de difang lianxi

P scholar other NOM place connect

'Oh scholar, and connect with other places'

In line 1 the participant initiates a checking self-repair through repeating his attempt at saying xuezhi ('scholar'). He identifies the trouble source as the pronunication of xuezhi ('scholar') by using rising intonation after both attempts where he interrupts his utterance to repeat it again with different tones and the same rising intonation, which indicates his need for feedback from the teacher. That this is an appeal for feedback is confirmed by the teacher's offering of the correct tones for xuezhi ('scholar') 'scholar' in line 3, to which the participant responds by indicating his understanding ('oh') in line 4 before continuing with his speaking turn.

1 P3: 如果他们 不能说 +不会+说汉语(.)他们不知道 ruguo tamen $<$ bu neng shuo $>$ bu hui shuo hanyu tamen bu zhidao if they $<\mathrm{N}$ able speak $>\mathrm{N}$ can speak Chinese they $\mathrm{N}$ know 
他们自己的<权力>他们的 rights?

tamen ziji de quanli tamen de rights?

they own NOM rights they NOM rights?

'If they $<$ not able to speak $>$ can't speak [Mandarin] Chinese

they don't know their own $<$ rights $>$, their "rights"?'

In line 2 in example (10) above, the participant initiates the self-repair by substituting the word quanli ('right's) in the preceding phrase tamen ziji de quanli ('their rights') with the word 'rights' in English marked with rising intonation. While this may seem like a question, the participant offered an explanation supporting her use of the checking selfrepair practice:

(11) It has two meanings...you have rights and you have power...I know the way the teacher looks at me like 'shenme chuanli?' (what rights/power?), which meant I had to say it in English. (P3)

Participants used checking for several purposes. In Example (9), the function of checking self-repair was for language learning, since the participant signalled his need for feedback on his utterance by self-repairing with altered forms of repetition and rising intonation.

The participants also used checking for this purpose when guessing how to use particular words in Mandarin Chinese as attested by participant 1 in relation to another instance of "checking” self-repair:

(12) I had never used the word before in that context and I didn't know whether to say 'zhou' or 'sheng' which have roughly the same meaning. (P1)

However, in Example (10), the purpose of checking was to ensure comprehension. In other words, the participant was sure about the word and needed no feedback, but perceived the hearer's need for clarification, which prompted her selfinitiated self-repair.

\section{Repetition:}

Although repetition is not a self-repair practice in itself, participants used it frequently as a precursor to some self-repair practices such as replacement. This is to be expected since repetitions are considered "part of the self-repair organisation when their function is to gain linguistic and/or cognitive planning time for the speaker” (Rieger 2003: 47). Data from the stimulated-recall interviews confirms that participants used repetition as a resource associated with self-repair practices, as described by P2:

(13) Often I will begin a sentence without really knowing how it's going to end. So in that recording, for example, I would say 'tamen, tamen, tamen...'. That is my brain thinking about how to construct a sentence and my mouth buying me time. (P2)

Furthermore, the participants often noted that their own perceptions of what was important in the conversation influenced the way they monitored and self-repaired. For example, all participants felt that tonal accuracy was less important than fluency or 
grammatical accuracy. Participants 1 and 2 noted their preference for communicative language use, while Participants 3 and 4 focussed more on grammatical accuracy.

That self-repair can be used for these various functions shows that self-repair behaviour is not simply an automatic process dependent on the learner's monitoring and correction of grammatical errors in accordance with their level of L2 proficiency. In other words, the participants showed meta-awareness of the different purposes of self-initiated self-repair.

\section{DISCUSSION}

The use of self-repair analysis to reveal information about language acquisition, monitoring ability or proficiency level can be hindered by its controlled use for purposes that lie beyond the scope of grammatical error correction and resolving misunderstandings. Studies that have used analysis of self-repair to reveal information about an L2 learner's language acquisition (Seliger 1980), monitoring ability (O'Connor 1998), or proficiency level (Bardovi-Harlig and Dornyei 1998; Chen 1990; Fincher 2006; van Hest 1996) have thus often misrepresented the complexity of self-repair practices in classroom talk by failing to recognise that the purposes for which learners use self-repair reach well beyond the two that are well-known, namely, grammatical error correction and resolving misunderstandings. As previously noted, studies of self-repair in L1 interactions have found it encompasses practices that attend to troubles in speaking, hearing, and understanding talk in conversation (Schegloff 2000: 207), with this finding being extended to studies of self-repair by L2 speakers (Rieger 2001, 2003a, 2003b; Rylander 2009; Wong 2000, 2005). Nevertheless, analysis of self-repair can provide some insight into learners' general perceptions and conceptualisation of the target language, their areas of difficulty, and their language acquisition strategies and attitudes.

Some studies have claimed that self-initiated self-repair can give instructors insight into a learner's progress in becoming proficient in the L2 (Camps 2003; Fincher 2006; Kormos 1999a; Lyster 1998). However, in our study, examination of the self-repair data revealed only minimal information about what each participant can and cannot say appropriately and correctly in Mandarin Chinese, in other words, their L2 proficiency. The self-initiated self-repairs that they produced were not a direct indicator of their proficiency, and instead appeared to be a manifestation of their own perceptions of what they do and do not know. The most common example in our study involved participants using self-repair for "addition" and "checking" when they were uncertain about the grammaticality or appropriateness of what they had said, or perceived they were unable to express their intended meaning adequately. Self-repair for other purposes could not be considered an indicator of proficiency level either, since participants' varying motivations and classroom variables influenced their production. The participants produced these self-repairs to serve different purposes within a particular situated context, in a way that was more controlled than the self-repairs they produced as a result of automated grammatical error-detection.

Studies linking proficiency with self-repair often refer to differences in the frequency of self-repairs between learners of high and low proficiency levels. However, this study points towards the existence of a more nuanced relationship between frequency of self-repair, proficiency level, and the amount of speech produced. As all four 
participants considered to be at approximately the same proficiency level, variation amongst them in regards to their frequency of self-repair appeared to be primarily related to the amount of speech they produced (cf. Seliger 1980). Those who spoke more produced more self-repairs. This study did not explicitly investigate factors influencing the amount of speech produced, but we believe one major influence is likely to be L2 learning experience, although research directed more specifically to this issue is needed. We recognise that since high proficiency learners have had more experience speaking the target language this could result in their higher frequencies of self-repairs compared to low level learners. Either way, the idea that a certain proficiency level can be matched with a particular frequency of self-repairs was not lent any support in this study, suggesting that the relationship between self-repair and proficiency level is less straightforward than previously assumed.

Our study also found that self-repairs of grammatical errors, or a lack thereof, cannot be used to infer conclusively what the learner can/cannot do and does/does not know. Camps (2003) suggested that errors which the learner repairs can indicate only what the learner knows explicitly, since the learner must use their own knowledge to both detect the error and correct it. However, the participants noted that sometimes, even though they knew the correct form, they chose not to repair a grammatical error they had made and could correct, because their focus was on what they considered to be more important aspects of the conversation. This finding therefore challenges the notion that monitoring by learners relies on their proficiency level, since the participants were able to choose not to self-repair in order to focus on something other than what their proficiency allowed them to do. Furthermore, many of the instances of self-repair in response to perceived errors were associated with uncertainty - about correctness or whether others had understood - rather than participants' actual knowledge of, and attempts to correct, their grammatical errors. The results of this study, although not conclusive, thus indicate that much more caution should be taken in researching any possible correlation between learners' self-initiated self-repair practices and their proficiency level.

The analysis of the classroom interaction and interview data also indicated that the ways in which learners conceptualise semantic and syntactic aspects of the target language also forms part of their knowledge about the language, which then impacts upon their proficiency. Their progress and success in acquiring those concepts can be interpreted from the nature and content of their "replacement" and "addition" selfinitiated self-repair practices, since these practices provide indications of what the speaker perceives to be incorrect, inappropriate or ambiguous based on the trouble sources to which they orient themselves. Learners do not necessarily make these selfrepairs to correct their grammatical errors, but rather to edit, alter and incorporate words and phrases that they perceive to be more appropriate, or to convey more accurately their intended meaning(s), as is the case for self-repairs by L1 speakers. Thus, how participants self-repair to reflect their intended meaning reveals information about their conceptualisation and understanding of the semantics and syntax of the target language, since it is this perception that leads them to self-repair in the first place. While this may not be direct evidence of their proficiency level or knowledge of the target language, it does reflect the speakers' perception of their own ability.

As for using self-repair data to determine monitoring ability, our study found that such an approach is also potentially problematic. The participants noted that the specific 
focus of their monitoring depended on what they deem important in the conversation. As a result, their self-repairs do not necessarily accurately reflect their perceived monitoring ability, since what they monitor varies according to contextual and situational demands, and thus they may choose to let potential trouble sources pass without initiating self repair. However, a consistently high frequency of certain types of self-repairs did indicate the participants' monitoring preferences, a finding that was confirmed by the interview data. For example, Participant 2 who advised he was more focused on communicative uses of Mandarin Chinese, produced a relatively high number of self-initiated self-repairs associated with expressing meaning, for example, "addition” self-repairs. Interestingly, each of the participants expressed no desire to monitor for tonal accuracy.

The final important aspect investigated was whether self-repair analysis can provide insight into an L2 learner's progress in language acquisition. The self-repair data reflected only minimally language acquisition resulting from participants' uptake of teacher feedback or the outcome of using the communicative self-repair strategies. Since self-repairs are considered to be at the forefront of the learner's interlanguage, they are said to provide evidence of what the student is acquiring (Lyster 1998; Swain 1995). This study offers some evidence that the participants did incorporate teacher feedback in their production of self-initiated self-repairs, particularly when "checking" or "asking in Mandarin Chinese". This is most likely due to the uncertainty that heightens their receptivity to such feedback, an interpretation supported by the stimulated recall interview data. However, although we did not investigate the long term effects of this, several instances in the data indicate this uptake is only short term. There were also numerous instances where participants did not incorporate feedback in their subsequent talk due to situational constraints, as they acknowledged during the interviews. This suggests that self-repair constitutes a limited means of gauging language acquisition.

Both the classroom interaction and the stimulated recall interview data confirm that while examining self-initiated self-repair practices can provide some information about a particular learner to some extent, the conclusions that can be drawn from such practices are not as straightforward as previous studies have suggested. It is also apparent that self-repair is not purely an automatic process for resolving misunderstandings, and this lack of automaticity interferes with its usefulness as an indicator of proficiency or language acquisition. However, learners' self-repair behaviour can still enable us to gain some useful insights. For example, the participants frequently employed various selfrepair practices to seek feedback from the teacher and others, especially when the participants were uncertain about correctness of their articulation. This suggests it may be possible to understand learners' areas of difficulty, or at least their perceived difficulties, based on repeated instances of self-repairs being triggered by similar trouble sources.

Furthermore, since learners also employ self-initiated self-repairs for language learning purposes, their self-repair behaviour may reveal the kinds of strategies learners employ in language learning. These strategies may even be enhanced by paying attention to the students' self-repair behaviour. From this study it seems that some self-initiated self-repair practices, particularly "code-switching" and "asking in Chinese", are not effective for long term second language learning. The participants agreed with this observation in the interviews, although nevertheless used them in classroom interactions. It seems that learners continued to use these strategies despite their limited long term effectiveness as learning tools in order to ensure successful communication. While more 
research into the effects of these strategies is needed, students could benefit from being encouraged to use other self-repair practices instead (see Rieger 2003b).

Self-initiated self-repair still plays an important role in the second language learning environment. Indeed, the repertoire of self-repair strategies used by the participants appears to be broader than previous taxonomies suggest. This, in addition to the analysis of the numerous functions of self-repair beyond simply automatic grammatical error correction and resolving misunderstandings, underscores the importance of self-repair in the language classroom.

\section{CONCLUSION}

One purpose of this study was to examine whether self-initiated self-repairs can be used for purposes beyond grammatical error correction, a finding which would impact upon the potential utility of self-repair for gauging proficiency, language acquisition and monitoring focus. Both the stimulated recall interview and classroom interaction data indicate that learners use self-repair for a much wider range of functions than is often assumed. This finding confirms that using self-initiated self-repair data as an indicator of proficiency level, language acquisition or monitoring ability may be a much more complex undertaking than thought, as previously noted by Rieger (2001, 2003b). This has implications for studies which use performance data to gauge language proficiency and acquisition more generally, as this indicates that it is difficult to tap into an underlying or assumed competence on the basis of performance in situated interaction.

In terms of gauging proficiency or language acquisition, self-initiated self-repairs could not be interpreted according to our analysis as clearly indicating what learners were monitoring and therefore what they know. Since learners do not self-repair every trouble source they detect and since not all self-repairs are evident to an observer, any insights gained through such an analysis into a learner's monitoring ability may only be superficial. The self-repairs that are produced may reflect only part of what the learner has monitored. It appears that the learners' preferences and perceptions play a larger role in how they self monitor than previously acknowledged.

The findings of this research therefore suggest that the connection between proficiency and self-repair is weaker than earlier studies have claimed. First, the participants tended to self-repair not as a result of their actual knowledge, but rather according to what they felt they did or did not know. This indicates that some instances of self-repair are related to perceptions of ability rather than actual ability, although others clearly remain linked to proficiency as found in previous studies (O'Connor 1998; Rieger 2001). Second, participants noted that they self-repaired with different motivations, which were not always consistent with their knowledge of correct forms (cf. Lennon 1994).

Our research findings also reveal the validity of self-repair analysis as an indicator of language acquisition is less clear-cut than earlier studies have indicated, confirming earlier studies on L2 speakers of other languages (Rieger 2001, 2003a). While some participants were found to incorporate feedback to their self-repairs and produce consistent modified output, others were found to acknowledge but not incorporate teacher feedback into their subsequent talk. The overall inconsistency with which participants produced self-repairs subsequent to teacher feedback on earlier grammatical errors 
suggests that it may not be an accurate indicator of language acquisition. However, the long term learning effects of uptake of teacher feedback have yet to be thoroughly examined. Although some participants in this study did initiate self-repair as a result of earlier teacher feedback, whether this truly reflects lasting acquisition remains uncertain.

How participants used self-repair for different functions did, however, indicate other information about the participants, particularly their perceived and actual areas of language difficulty, how they conceptualise and perceive the target language, and their language learning strategies. Examining an individual's self-repair behaviour may thus reveal more than has been thought hitherto.

Finally, as our study was limited to four participants, the findings from it remain to be confirmed by replication on a larger scale and across various proficiency levels, to enable more accurate and useful comparisons. Our study suggests that past exposure to the L2 influences the individual communication styles of learners. Another avenue of future research is thus to investigate the differences between learners from immersion and home country classroom backgrounds through an examination of the frequency and type of self-repairs these different groups produce.

\section{NOTES}

1. The data excerpts are presented in three rows: the first two rows are a transcription of the interactions in Chinese characters and Pinyin respectively. The third row is a wordby-word gloss. A translation into English follows at the end of speaking turn.

\section{ACKNOWLEDGEMENTS}

We would like to thank the anonymous reviewers for their very thoughtful and helpful feedback on an earlier version of this paper.

\section{REFERENCES}

Bardovi-Harlig, K. \& Dornyei, Z. (1998) Do language learners recognize pragmatic violations? Pragmatic vs. Grammatical awareness in instructed L2 learning. TESOL Quarterly 32, 233-259.

Buckwalter, P. (2001) Repair sequences in Spanish L2 dyadic discourse: A descriptive study. The Modern Language Journal 85 (3), 380-397.

Camps, J. (2003) The analysis of oral self-correction as a window into the development of past time reference in Spanish. Foreign Language Annals 36, 233-242.

Chen, S-Q. (1990) A study of communication strategies in interlanguage production by Chinese EFL learners. Language Learning 40 (2), 155-187.

Fincher, A. (2006) Functions of self-initiated self-repair in an advanced Japanese language classroom. Unpublished PhD Dissertation. Griffith University: Australia. 
Fox, B. \& Jasperson, R. (1996) A syntactic exploration of repair in English conversation. In P. Davies (Ed.), Alternative Linguistics. Descriptive and Theoretical Modes (pp. 77134). Amsterdam: John Benjamins.

Fox, B., Hayashi, M. \& Jasperson, R. (1996). Resources and repair: a cross-linguistic study of syntax and repair. In E. Oches, E. A. Schegloff \& S. A. Thompson (Eds.), Interaction and Grammar (pp. 185-237). Cambridge: Cambridge University Press.

Hayashi, M. (1994) A A comparative study of self-repair in English and Japanese conversation. In N. Akatsuka (Ed.), Japanese/Korean Linguistics. Volume Four (pp. 7793). Stanford, CA: CSLI.

Kormos, J. (1998) A new psycholinguistic taxonomy of self-repairs in L2: A qualitative analysis with retrospection. The Even Yearbook 3, 43-68.

Kormos, J. (1999a) Monitoring and self-repair in L2. Language Learning 49 (2), 303342.

Kormos, J. (1999b) The effect of speaker variables on the self-correction behaviour of L2 learners. System 27 (2), 207-221.

Kormos, J. (2000) The role of attention in monitoring second language speech production. Language Learning 50, 343-384.

Lennon, P. (1994). Self-correction and error in advanced learner spoken narrative. In G. Bartelt (Ed.), The Dynamics of Language Processes. Essays in Honor of Hans W. Dechert (pp. 85-103). Tübingen: Gunter Narr Verlag.

Levelt, W. J. M. (1983) Monitoring and self-repair in speech. Cognition 33, 41-103.

Liebscher, G. \& Dailey-O’Cain, J. (2003) Conversational Repair as a Role-Defining Mechanism in Classroom Interaction. The Modern Language Journal 87 (3), 375-390.

Lyster, R. (1998) Negotiation of form, recasts, and explicit correction in relation to error types and learner repair in immersion classrooms. Language Learning 48 (2), 183-218.

Mackay, D. (1987) The Organisation of Perception and Action: A Theory for Language and Other Cognitive Skills. New York: Springer.

O’Connor, N (1988) Repairs as indicative of interlanguage variation and change. In T. J. Walsh (Ed.), Synchronic and Diachronic Approaches to Linguistic Variation and Change. Georgetown University Roundtable 1988 (pp. 251-259). Washington, D.C.: Georgetown University Press. 
Rieger, C. L. (2001) Self-Repair Strategies of English-German Bilinguals in Informal Conversations: The Role of Language, Gender and Proficiency. Unpublished Phd dissertation, University of Alberta: Canada.

Rieger, C. L. (2003a) Repetitions as self-repair strategies in English and German conversations. Journal of Pragmatics 35 (1), 47-69.

Rieger, C. L. (2003b) Some conversational strategies and suggestions for teaching them. Die Unterrichtspraxis/Teaching German 36 (2), 164-175.

Rylander, J. (2004) Interaction in a Chinese language as a foreign language classroom: A conversation analysis approach. Second Language Studies 23 (1), 67-144.

Rylander, J. (2009) Repair work in a Chinese as a foreign language classroom. In H. thi Nguyen \& G. Kasper (Eds.), Talk-in-interaction: Multilingual Perspectives (pp.245-280). Honolulu: National Foreign Language Resource Centre, University of Hawai'i at Manoa.

Schegloff, E. A. (1979) The relevance of repair to syntax-for-conversation. In T. Givón (Ed.), Syntax and Semantics Volume 12: Discourse and Syntax (pp. 261-286). New York: Academic Press.

Schegloff, E. A. (1997) Practices and actions: boundary cases of other-initiated repair. Discourse Processes 23 (3), 499-545.

Schegloff, E. A. (2000) When 'others' initiate repair. Applied Linguistics 21 (2), 205-243.

Schegloff, E. A., Jefferson, G., \& Sacks, H. (1977). The preference for self-correction in the organization of repair in conversation. Language 53 (2), 361-382.

Schmidt, R. W. \& Frota, S. N. (1986) Developing basic conversational ability in a second language: A case study of an adult learner of Portuguese. In R. R. Day (Ed.), Talking to Learn: Conversation in Second Language Acquisition (pp. 237-326). Rowley: Newbury House.

Selinger, H. (1980) Utterance planning and correction behaviour: Its function in the grammar construction process for second language learners. In H. W. Dechert \& $\mathrm{M}$. Raupach (Eds.), Towards a Crosslinguistic Assessment of Speech Production (pp. 87-99) Frankfurt, Germany: Peter Language.

Smith, B. (2008) Methodological hurdles in capturing CMC data: The case of the missing self-repair. Language Learning \& Technology 12 (1), 85-103.

Swain, M. (1995) Three functions of output in second language learning. In G. Cook \& B. Seidlhofer (Eds.), Principles and Practice in Applied Linguistics: Studies in Honour of H. G. Widdowson (pp. 125-144) Oxford University Press. 
Temple, L. (1992) Disfluencies in learner speech. Australian Review of Appolied Linguistics 15 (2), 29-44.

van Hest, E. (1996) Self-repair in L1 and L2 Production. Tilburg: Tilburg University Press.

van Hest, E., Poulisse, N. \& Bongaerts, T. (1997) Self-repair in L1 and L2 production: an overview. ITL, Review of Applied Linguistics 117-118, 85-115.

Wong, J. (2000) Delayed next turn repair initiation in native/non-native speaker English conversation. Applied Linguistics 21 (2), 244-267.

Wong, J. (2005) Sidestepping grammar. In K. Richards \& P. Seedhouse (Eds.), Applying Conversation Analysis (pp. 159-173). Basingstoke, Hampshire: Palgrave Macmillan. 